rosis by dyspeptic disorders. Arnold furnishes us with an interesting example of this sympathy between the ear and the stomach in the case of a child who suffered from chronic vomiting which defied for a long time all curative measures, but was immediately removed on the extraction from each ear of $a$ bean which had been introduced in play.

There is on record a case of dysphonia caused by spasm of the left true vocal cord, and accompanied by pain in the left par. This spasm was considered to depend, in all probability, on the pressure of the left vagus, where the recurrent laryngeal branch is given off, by an aneurism; but several examinations failed in eliciting any proof of the existence of a tumour. The patient complained bitterly of the pain in the ear, and stated that it was "a piercing pain right inside"-endeavouring to enforce his remark by inserting his finger in the meatus. No allusion is made by the reporter of the case to the condition of the auditory canal, which was probably not examined.

Dr. Gull states that pain in the ear is not uncommon in connexion with thoracic aneurisms. My own experience, however, does not support this opinion; for only once have I encountered aural pain in connexion with that disease. Although the presence of a tumour was not demonstrable, yet all the symptoms undoubtedly pointed to the existence of some body pressing on the left recurrent laryngeal nerve in its thoracic course. The irritation by the same tumour of one or more of the numerous pulmonary or cardiac branches of the vagus in such close vicinity would readily account for the pain in the ear. The explanation already given of the sympathy between the ear and the larynx applies in this case, if the direction from which the impression starts be reversed.

In conclusion, the foregoing observations may thus be summed up :-

1. The sympathy between the ear and the larynx, as well as the stomach, has been long known, although the majority of recent writers seem to have overlooked it.

2. This sympathy is not manifested in every individual, but in about seventeen per cent., and seems to depend on a state of hyperæsthesia of the nerve which supplies the auditory canal.

3. The nerve of the ear concerned in the production of this phenomenon cannot be a branch of the vagus, as Romberg and Toynbee have affirmed, but is in all probability a branch of the fifth cranial nerve.

4. This sympathy is an example of a reflected or sympathetic sensation, in which the connexion between the nerves concerned takes place in the nervous centre.

5. Cases occasionally occur where a cough is solely dependent on the existence of some source of irritation in the auditory canal.

6. The explanation of the sympathy between the ear and the larynx enables us to understand the mode in which pain of the ear becomes occasionally a symptom of a thoracic aneurism.

One of my chief objects in bringing before the notice of my professional brethren this sympathetic connexion is to introduce to them what may be called an ear-cough, and to strongly advise them to examine the auditory canals in all cases of obstinate cough, where none of the more frequent causes of this symptom can be discovered.

Scarborough, $\Lambda$ l)il, 1866

\section{ON GENERAL DIPHTHERIA.}

BY JAMES FOWLER, EsQ., M.R.C.S.,

HON. SURQEON TO CLAYTON'S HOSPITAI AND DISPENSARY, WATRTIKLD.

IN addition to an unusual number of cases of scarlatina and erythematous sore-throat in this district, there have lately been several of true diphtheria. At the beginning and height of the epidemic, though there was considerable prostration, the local symptoms were most characteristic - limited in a general way to the fauces, and accompanied by well-marked fibrinous exudation, slowly thrown off, and re-formed many times, perhaps, before the issue of the case either in death or recovery. Latterly, however, such isolated manifestations have been less frequently observed. Instead, alarming general depression has been amompanied by a peculiar kind of inflammation, varying much in its intensity, in the organ which it primarily affects, and in the amount of fibrin which it deposits; but constant in the suddenness of its appearance, the insidi- ousness and ungovernableness of its progress, and the speedy fatality of its termination. Good illustrations of both forms occurred in an outlying, ill-drained village, built partly round a large sheet of almost stagnant water, strongly impregnated with decaying vegetable matter; bronchocele being so common here that it may almost be said to be endemic. It must be added, however, that scarcely less serious instances have been noticed in the town itself, and in situations where not only the circumstances and occupations of patients, but the drainage, ventilation, and construction of their homes, were everything that could be wished. The following is selected, not only on account of the infrequency of such cases, and the still greater scarcity of adequate records of them, but because there are several accidental circumstances connected with it which add materially to its interest.

Mary $\mathrm{A}-$, agel thirty-nine, of temperate and regular habits, at home with a married sister in one of the healthiest parts of the town, without having been at all exposed to cold or wet, went to bed on March 10th complaming of a little sore-throat, with hoarseness and difficnlty of swallowing. Of this, however, thinking it proceeded from cold, she took no notice until towards morning, when it became much worse, and increased until about eight A.M. on the $20 \mathrm{th}$, when I was sent for, and found her propped up in bed, breathing noisily and with much difficulty. There neither was nor had been any cough or expectoration of any kind, but she was very anxious and prostrate, and spoke huskily or in a whisper, evidently with much pain and effort. Placing her finger on the pomum Adami as the seat of chief suffering, she said, "It is all here-choking." The mouth could not be got sufficiently wide open for the throat to be properly examined, the parotid and submaxillary glands on the right side being swollen and tender; but there was evidently a good deal of diffused redness in the fauces, especially about the tonsils. There did not appear to be any mischief in the chest; but it was difficult to speak accurately for this, as loud croupy laryngeal breathing quite hid all finer sounds in whatever part of the chest the stethoscope was placed.

Under the impression that I had got to deal with a case of acute laryngitis, I simultaneously fomented the throat with hot water and sponges, applied blistering liquid to the back of the neck, and gave forty grains of powdered ipecacuanha in water. The dose was swallowed only with much pain and difficulty, and, though repeated in ten minutes, produced neither the slightest attempt at vomiting nor the least improvement in the breathing. The latter was, in fact, so much worse at the end of half an hour, the pulse so rapid and yet so faint and irregular, the countenance so pale and dusky, that suffocation seemed imminent, and laryngotomy was accordingly performed. There was nothing remarkable in the operation; only slight bleeding occurred, and that ceased the moment the larynx was opened. The relief obtained, though very considerable, was not perfectly satisfactory. The breathing was at once made quite easy, and, as a large canula was used, almost noiseless; the pulse, though still very soft, became regular, fuller, and less frequent; but the countenance had a cadaverous expression, and sallowness and anxiety marked on it, for which there was no adequate explanation, especially as the chest was found (and it could now be examined accurately) perfectly healtby. Four hours afterwards, in order to obtain efficient nursing and attendance, she was removed in a close cab to the hospital - a distance of only a few hundred yards ; and wrapped in blankets, with a couple of large sponges previously immersed in boiling water applied to the throat, every possibility of a chill being taken was avoided; the skin was, indeed, very soon after, quite moist and perspiring. There being considerable inflammation of the tonsils, besides external swelling and infiltration of the subcutaneous areolar tissue in front of the neck, with swelling and tenderness of the lymphatic glands on both sides, six leeches were applied, which gave immediate relief, at least so far as the pain was concerned. But before evening it was evident that a smart attack of bronchitis was impending, loud rhonchi being audible all over the chest. The room was accordingly kept uniformly at $60^{\circ} \mathrm{F}$., and the air saturated with watery vapour, at the same time that diaphoretic doses of antimony were given, and the bowels cleared by calomel and salts.

The night was passed restlessly, and a careful examination. in the morning (March 2lst) showed that the inflammation had spread to the smaller tubes throughout the chest; the larger ones by this time containing viscid mucus, which was expectorated with great difficulty. The back of the left lung, besides, was dnll; but all fine anscultation was out of the question, loud rattles, and growling, groaning, and snoring 
sounds, being mixed discordantly, and hiding anything less obtrusive. There was evidently great pain in both sides and across the chest; and respiration was performed, with difficulty, about 42 times in the minute. Pulse 116, small and thready. Tongue very thickly coated with brown moist furr. Temperature of body, $99 \cdot 75^{\circ} \mathrm{F}$. Egg, wine, and beef-tea were given freely through the day, and had by this time become absolutely necessary.

The night was again passed restlessly, and in the morning (March 22nd, ten A.M.) all the unfavourable symptoms had much increased in severity. The pulse was very unequal and irregular, and at the same time so feeble and rapid that it could not be counted; and the breathing was hurried, and very badly done. The heart beat very tumultuously, a soft bellows murmur accompanying each systole. In other parts of the chest nothing could be heard but a loud medley of moist and dry sounds. Percussion was not used, because of the great pain which an attempt occasioned. The temperature of the body was taken very carefully, and found to be $99 \cdot 6^{\circ} \mathrm{F}$. There was total suppression of urine. She was evidently sinking rapidly; but the countenance, though pale and somewhat jaundiced, was particularly expressive, indicating the deepest anxiety; and the intellect, which was remarkably acute for a person in her station, remained perfectly unclouded until within half an hour of death, which took place at two P.M., calmly and very gradually.

Post-mortem examination - The submaxillary region on the right side was much swollen and hardened; the skin in front of the neck in places congested and livid; and the subcutaneous areolar tissue infiltrated with bloody serum. The tonsils and mucous membrane of the top of the pharynx were tumid and of a deep-claret colour; roughened by recent deposit of soft and inelastic fibrin, nowhere thick enough, howev'er, to be readily peeled off, or merit the title of false membrane. The nesophagus itself was healthy; but the submucous tissue at the back of the larynx was deeply infiltrated by a yellowish-grey pasty material, which, like the surface pellicles, was found under the microscope to consist entirely of nucleated cells embedded in a granular or amorphous substance like ground glass in appearance, devoid of fibrillation-at least no fibres or trabeculæ could be made out at all distinctly. Leaving the digestive system unaffected, the inflammation passed down the larynx and trachea, the mucous membrane of both which was throughout either deepred or mahogany-coloured, except here and there, where it appeared whitish-grey or yellowish, in consequence of the deposit being thicker and more opaque. The aperture of the glottis, though pervious, was much narrowed by æedematons swelling, and, together with the epiglottis and arytenoepiglottidean folds, coated with loose, flocculent, or shreddy fibrin. The epiglottis itself was much thickened, tumid, and more rigid than natural. The whole of the mucous membrane of the bronchial tubes, even down to the last ramifications, was deeply injected and roughened by recent deposit; but much mucus or fluid of any kind was not found, what little there was being transparent and extremely adhesive. Both lungs were intensely congested, especially behind and below, where hepatization was complete, pieces sinking like ston'es on being thrown into a basin of water. A little lung in front and towards the apex on the right side was crepitant, and, though very dark-coloured externally, allowed a quantity of frothy serum and blood to escape on being sliced. Both pleuræ were universally lined with recently-deposited lymph, and distended with straw-coloured, flaky serum, except where there were adhesions. The pericardium was also inflamed, tensely distended with clear yellowish fluid, and glued to the diaphragm; lined internally with rough, warty fibrin. The heart itself appeared healthy. The liver was a uniform mass of hobnail, but indicated no recent alteration, except that it was gorged with bile, with which, also, the gall-bladder was distended. The spleen was about three times the natural size, and softened. The kidneys were both of them enlarged and congested, the right particularly so. The bladder was pale and contracted, but with a catheter about two drachms of urine were drawn off into a test-tube. The mucous membrane of the vulva and vagina had apparently been recently inflamed, though no complaint of this was made during life, and fibrin was deposited in considerable quantity. On warming a portion of the urine, first a cloud of lithate of soda disappeared, and then the whole became semi-solid from deposition of albumen. Dilute nitric acid added to this produced no change. On examining the rest microscopically, it was found to be so loaded with columnar epithelium, apparently from the ureter, besides containing flatter forms from the kidney and bladder, with many mucus cells, that one could scarcely help suspecting there must have been inflammation, at least of the ureter. There were also many particularly transparent tubule-casts, but no blood could be identified.

The above description, selected, as has been already explained, on account of its containing several accidental points of interest, brings out notwithstanding the following essential particulars and properties of diphtheria in a very striking manner :-

1. Fibrinous exudation coextensive with inflammation, whe ther of the fauces, tonsils, pharynx, larynx, trachea, bronchial tubes, lungs, pleuræ, pericardium, kidneys, vulva, or vagina.

2. Absence of any trace of suppuration, ulceration, or sloughing.

3. Enlargement of glands and infiltration of cellular mem brane in the neck.

4. Universal depression from the first, and lowness of tem perature; the latter never rising above $99 \cdot 75^{\circ} \mathrm{F}$., whereas in an ordinary pneumonia or pleuritis it would have been at least from $104^{\circ}$ to $106^{\circ}$.

5. Incipient nephritis ; suppressicn of urine; albuminuria; and the presence of peculiar casts in the urine.

In conclusion, I must thank my friends, Dr. Mercer and Mr. Milner, of Wakefield, for assisting me to make the autopsy in this case.

Wakefield, April, 1866

\section{ON HYPERTROPHY OF THE TOE-NAILS.}

\section{By GEORGE LEWIS COOPER, EsQ., F.R.C.S.,} SURGEON TO THE BLOOMSBCRY DISPFNSARY。

THE nails situated on the dorsal surface of the fingers and toes consist of the same cellular structure as the epidermis, with the exception of certain modifications. They are an appendage of the skin, firm and elastic in structure, at the same time are covered to a certain degree by folds of the cuticle, and are received into a hollow bed termed the matrix, whence they are supposed to derive their nutrimental cells and means of growth. These cells vary in their form, some being rounded, others elongated, or even flattened, and convey to the nail by their renewal an increase in its length and density, and, when completed, their perfect and laminated appearance. On observing the nature and characters of the nail in health or disease, we may remark considerable changes to take place in their form and structure, so as to enable us to determine these appearances as indications of a healthy or of a diseased action. Thus in health we find the nails to be of a pinkish colour, firm and dense in substance; but in phthisis they assume a paler hue, are delicate in consistence, and tapered or elongated in form, following the direction of the last digital phalanx. In cholera their colour is changed to a bluish or leaden hue; and in tertiary syphilis to that of a dark, unhealthy aspect, with ragged and irregular edges. In onychia maligna they become brownish, unhealthy, and of a low vitality; but in hypertrophy they are completely changed in structure, form, and density, having assumed all the attributes of horn, both in shape and consistence, which the accompanying drawing will clearly show. It is a case of hypertrophy of the

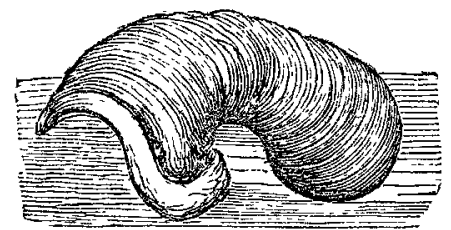

nail of the big toe of the right foot of a woman, which was removed by me, affording us at the same time the interesting fact of its hereditary tendency.

Jane $\mathrm{P}-$, aged thirty-seven, married, and has foù children. States that she has never suffered from syphilis, and has enjoyed almost uninterrupted good health, but now sadly complains of the horny condition of her big toe-nails, creating much pain and suffering; that of the right foot being of considerable size, and more developed than the left, but in substance that of perfect horn, curled and bending over the upper surfaces of the two adjoining toes. She relates the facts that her father was similarly afflicted, and that "her sister has precisely the same kind of big toe-nail." In consequence of the pain created by the pressure of a boot, she has consented 